\title{
TECTONIC REGIME OF THE SUBURBAN (SOUTHERN) AREA OF CHANIA CITY IN CRETE ISLAND BY USING GEOPHYSICAL METHODS
}

\author{
Komelidou C. ${ }^{1}$, Kirmizakis P. ${ }^{2}$, Soupios P. ${ }^{2}$, Savaidis A. ${ }^{3}$ and Tsourlos P. ${ }^{1}$ \\ ${ }^{1}$ Aristotle University of Thessaloniki, Department of Geology, 54124, Thessaloniki, Greece, \\ cgkomeli@geo.auth.gr,tsourlos@geo.auth.gr \\ ${ }^{2}$ Technological Educational Institute of Crete, 3 Romanou, Halepa, 73133, Chania, Crete, Greece, \\ panagiotiskirmizakis@gmail.com,soupios@staff.teicrete.gr \\ ${ }^{3}$ Institute of Earthquake Seismology and Earthquake Engineering, Ag. Georgiou 5, Pylaia, P.O. \\ Box 53, 55 102, Finikas Thessaloniki, Greece, alexandros@itsak.gr
}

\begin{abstract}
The transient electromagnetic method (TEM) has gained increasing popularity over the last years especially in hydrogeophysical and geotectonic applications. TEM-Fast 48HPC was used for collecting the sounding data during summer 2015. The main purpose of this work was the definition of the geotectonic characteristics at the Southern area of the city of Chania by means of TEM-Fast sounding survey which was carried out in the summer of 2015. Detailed geological survey was applied prior the geophysical measurements and all the available borehole logs were collected. All data were integrated to provide a reliable geotectonic model of the area under investigation. Joint faults systems were detected which are in agreement with previous geophysical and tectonic studies in the area. This work shows clearly the applicability and efficiency of the TEM in studying complex geotectonic environment.
\end{abstract}

Keywords: TEM, Tectonic, ID TEM Modeling.

\section{Пєрíi}

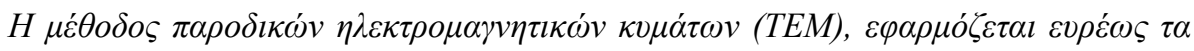

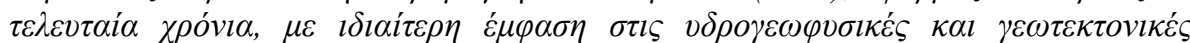

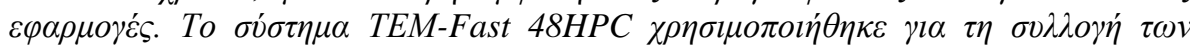

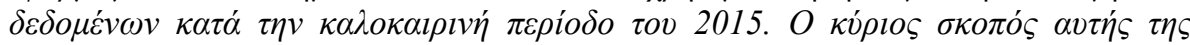

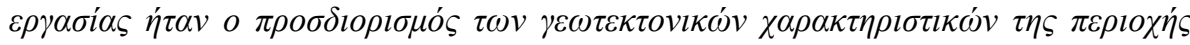

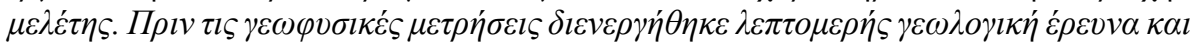

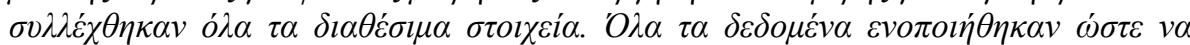

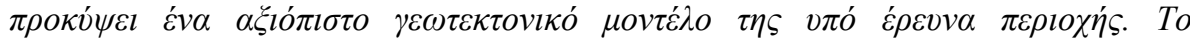

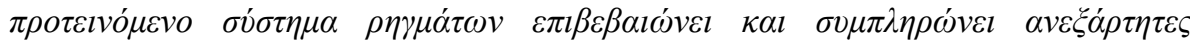

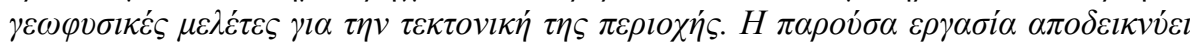

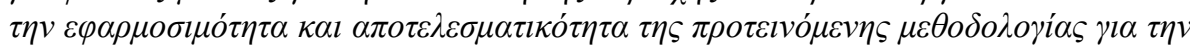

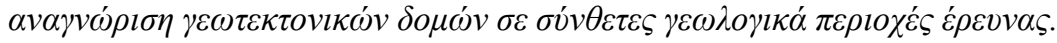

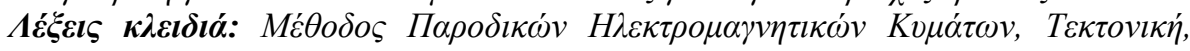

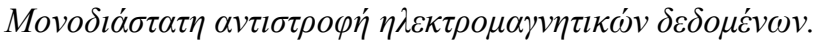




\section{Introduction}

The geophysical techniques offer a suitable method for depicting the tectonic and other subsurface characteristics of an area under investigation. Among all geophysical techniques (Gravity, GPR, Magnetics, Resistivity, Seismic refraction, etc.) electromagnetic methods are undoubtedly one of the leading ones in the exploration and management of sedimentary environments (Barsukov et al., 2007). TEM method has been used worldwide for many environmental surveys (including geotectonic studies) since several theoretical studies on the applicability of the method for environmental investigation were undertaken. The transient electromagnetic (TEM) method is a fast and cost effective method for exploring the subsurface. This paper describes a recent evaluation study of the applicability of the TEM method by using single loop 50x50m (coincident loop) for shallow-depth geological mapping for depicting the tectonic regime of the southern part of the urban area of Chania (Figure 1) in Crete Island (Southern Greece).

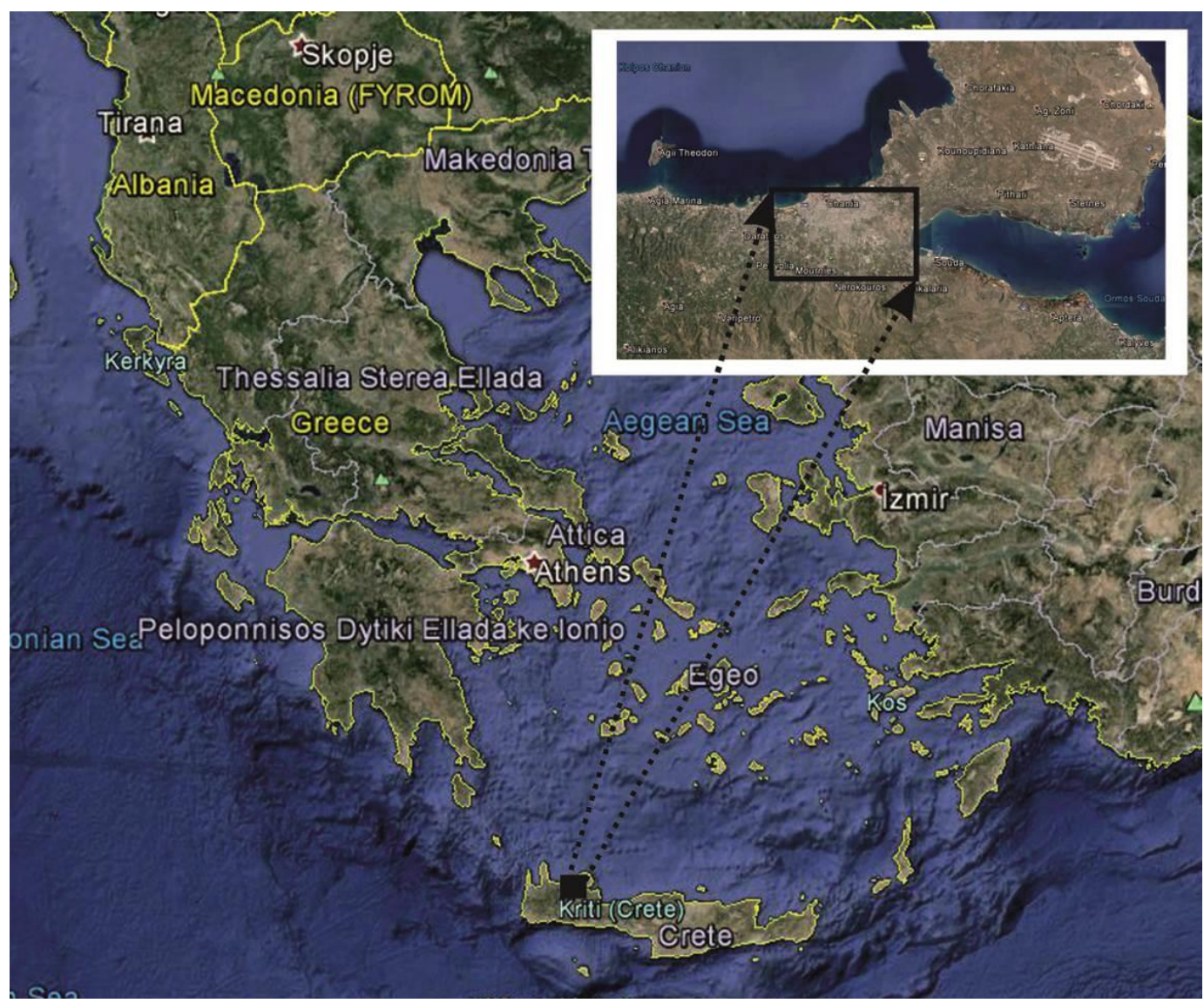

Figure 1 - The study area (black filled rectangle) and the locations where the TEM soundings were collected are presented (black rectangle in the southern part of Chania city).

\section{Geological and Tectonic Settings of the Study Area}

The study area situated at the southern part of the Chania urban area and about $3.5 \mathrm{Km}$ far from the city center. Based on Mountrakis et al. (2012), the broader area of Chania city (including the south ern suburbs) is characterized by the presence of an extended E-W fault zone and many sub-parallel to the north faults, forming the tectonic grabben of Myloniana - Mournies - Souda's Gulf. Many ot her faults with a general NW -SE direction were determined by other geological and geophysical m 
ethods (Papadopoulos, 2013; Koutsoupakis et al., 2013). The broader Chania study area consists of (Figure 2):

- Limestones with marls and sandstone intercalation found at the mountainous area to the South and North-East (at the Aktoriri area) of the study area.

- Miocene to Pliocene marls with sandstone and locally breccias and conglomerates covering the urban area of Chania city.

- The basin of Chania (South of the urban area and North of the bedrock formations) covered with Quaternary alluvial deposits and only assumptions regarding the tectonic features into the basin can be adopted.

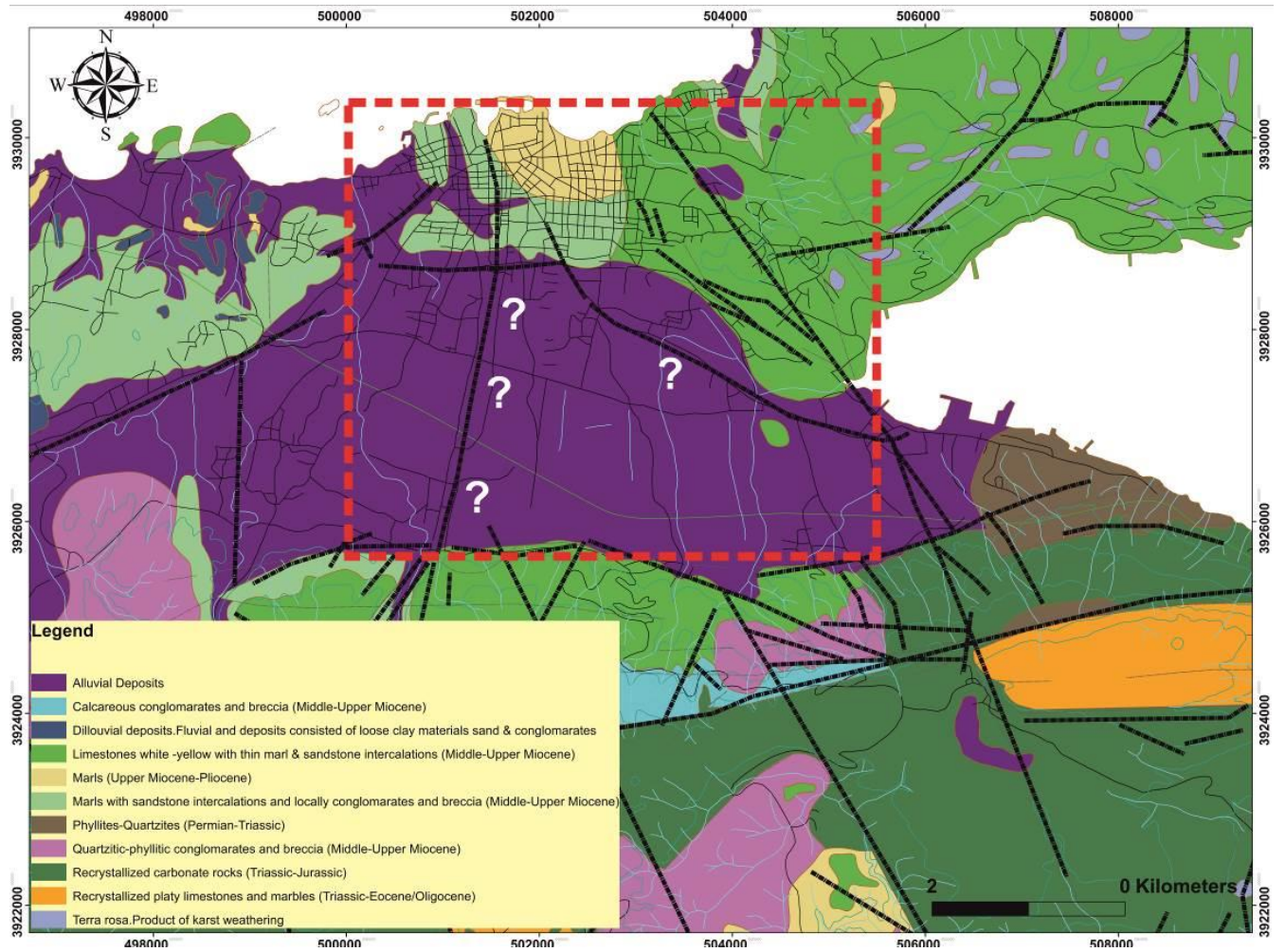

Figure 2 - The geological map of the broader Chania city area is shown. The study area is depicted by the red dashed rectangle and the white questions marks shown the locations of the invisible tectonic lines as it covered by the alluvial deposits.

\section{Geophysical Surveys at the broader study area}

Sarris et al. (2005) determined the morphometric units in the Crete Island and possible tectonic fea tures from the geological map as well as from the defined units were depicted. To test the validity of the aforementioned assumption, VLF measurements along a profile at the southern part of Chani a basin were contacted. Three fracture zones were depicted which were in agreement with the resul ted morphometric features and the geological maps. Recently, Papadopoulos (2013) collected seve ral geophysical data sets by applying three different geophysical methods (Figure 3). The data from ten (10) circular seismic arrays were acquired to provide the Vs structure till the maximum depth o f 300 meters. The main purpose was to define the depth to the bedrock, or the thickness of the marl $s$ in the urban area of Chania. Two hundred (200) HVSR (single station Horizontal to Vertical Spec tral Ratio) measurements were collected and processed to obtain the spatial distribution of soil amp lification, its resonant frequency and their correlation with the geology of the study area. Based on 
HVSR frequency peaks and soil classification (Papadopoulos et al., 2016), a N-S fracture zone is e xpected close to the area in which an ERT (yellow arrow in Figure 3) survey was conducted in 201 1 to clarify the existence or not of the fracture zone. None of the aforementioned methods was able to provide reliable information about the location of the fracture zone along the basin from South (as defined from VLF survey) to the North. In order to find the fault trace at the urban area of Chan ia, twenty-four (24) regularly spaced ReMI seismic measurements were acquired (Koutsoupakis $e t$ al., 2013) to determine the spatial and in depth distribution of Vs in the study area. The resulted mo dels were in good agreement with the geology and tectonic regime (the assumed N-S fracture zone) of the study area.

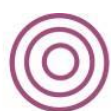

Seismic arrays, 2010 (Papadopoulos 2013)

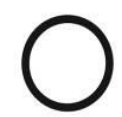

HVSR seismic, 2007-2009 (Papadopoulos 2013)

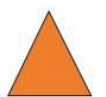

ReMi Seismics, May 2013 (Koutsoupakis et al. 2013)
Seismic arrays, July 2015

○ (Savvaidis et al. 2015)

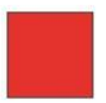

TEM survey, July 2015 (Komelidou et al. 2015)

VLF survey, March 2009 (Sarris et al. 2009)

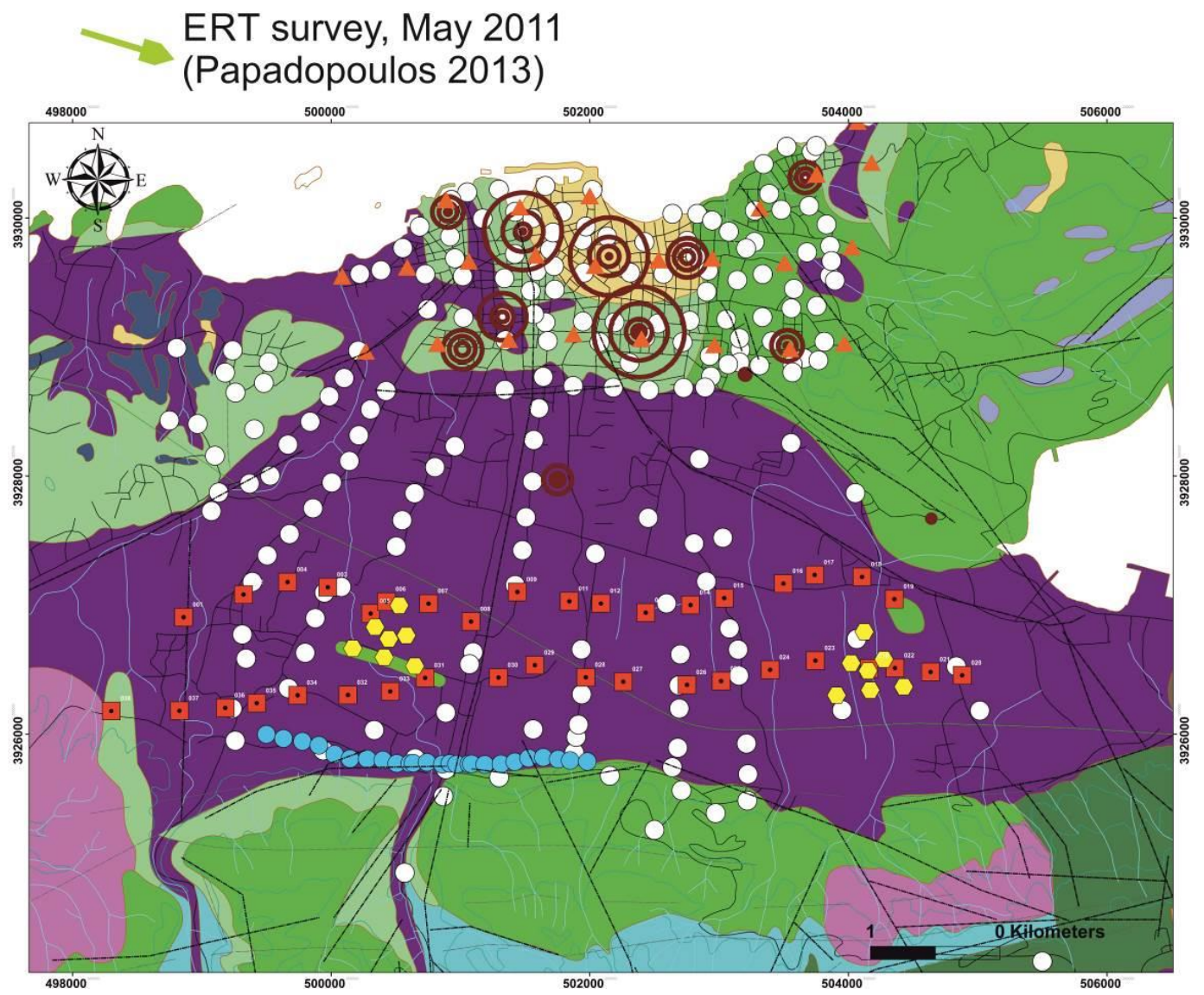

Figure 3 - A geological map with all the till now collected geophysical measurements in the b roader study area is presented. Several (6) geophysical methods have been applied since now to determine the complex tectonic regime of the broader study area. 
There is incomplete information on the location of the fracture zones in the Chania basin. For that $r$ eason, an extended geophysical survey took place in Chania basin during July 2015. Moreover, thir ty-eight (38) TEM soundings by using the TEM Fast 48HPC (REF) were collected along two W-E profiles as it is shown in Figure (3). Only the TEM results are going to be presented and commente $\mathrm{d}$ in comparison with the other available geophysical models as mentioned above.

\section{Geophysical Method Used}

The TEM method has been used in tectonic, engineering but also at difficult environmental problems over the last decade. A detailed description of the method is given by Barsukov et al. (2007) and it belongs to the category of controlled source EM methods. The TEM method makes use of a direct current transmitted into a square (Tx) loop lying on the ground creating a primary, stationary magnetic field. The direct current is switched off which induces an eddy current system in the ground. The current will decay and further induce a secondary magnetic field that is measured in the receiver $(\mathrm{Rx})$ coil. Since the secondary response is measured in the absence of primary field, the sensitivity to errors of Tx/Rx geometry is demising. The TEM method prevail high resolution on revealing conductive layers at depth, whereas the resolution of resistive layers is limited.

\subsection{Data Acquisition}

The TEM surveys were carried out by using a single square loop (used as transmitter and receiver) configuration with dimensions $50 \mathrm{~m} \times 50 \mathrm{~m}$ or $25 \times 25 \mathrm{~m}$, allowing an interpretation of the data in term $\mathrm{s}$ of the subsurface resistivity structure down to a depth of a maximum of 100-120m (depending on the subsurface resistivity). The system was set to transmit current up to 4 Amp with 32 active time gates from $4 \mu$ s to $1024 \mu$ s and the stacking time was approximately 3 minutes. In order to define and avoid aliasing effects (high frequency - HF noise) the measurements were repeated several tim es at each sounding location. A high accuracy GPS was used for the accurate (less than $1 \mathrm{~m}$ ) positio ning of the TEM soundings. The survey was conducted along profiles adopting an average distance between the sounding of about $200 \mathrm{~m}$. The preferred directions were W-E based on the expected te ctonic and geological characteristics of the study area (Figure 3).

In total, 114 soundings were measured in 38 locations (Figure 3), over a period of one week (July 2 015). Several soundings were taken at each location in order to accomplish the highest signal to no ise ratio. The average root mean square (rms) error of all the final soundings was less than $4 \%$.

\subsection{D TEM Modeling}

The TEM-RES software package was used for processing the raw data solving the inverse problem in time domain electromagnetic soundings. The receiver's transient voltages of each sounding are transformed into apparent resistivity to aid in the qualitative interpretation and inversion. The interpretation from Apparent Resistivity variation to 1D profile is achieved by the use of inversion.

Initially, for each sounding (Figure 4A), the best apparent resistivity versus (vs) time curve is selected in order to produce an inverted 1D, horizontal layered model. Processing of the raw TEM data yields a vertical profile of geological formation's as of apparent resistivity vs depth.

Specifically, initially regularization (smoothing and damping) parameters were applied to raw data in order to remove bad quality, noisy data (Figure 4B). After that, the filtered data are carried out by either the transformation (details can be find into the manual of TEM Research software), or by solving the inverse problem (in this case a piecewise-homogeneous section is calculated) in a class of layered media. Although both approaches have their own inherent significance and can be used independently, in the current study a joint form of these two approaches is used: initially the transformation results are calculated and then, these results used to construct the initial model for the inversion process (Figure 4C). Under this approach, the initial model for the inversion process is defined with respect to the study area characteristics. After all, the final inverted resistivity model 
is presented (Figure 4D) as a smooth curve (from transformation) and a piecewise-uniform (from inversion) diagram.

\subsection{D TEM Imaging}

The results from inverted 1D soundings are usually presented as the final interpretation. Generally speaking, the 1D modeling is inadequate to reconstruct and describe the subsurface, especially whe $\mathrm{n}$ a complex (due to tectonic) subsurface structure is expected. Thus, 2D imaging is required due to its ability to construct pseudosections. In the forthcoming geoelectrical sections, red colors represe nt high resistivity formations (e.g. alluvial sediments), green and yellow colors demonstrate the me dium to low resistivity formations (unsaturated and saturated marls and sandstones), while the blue colors depict the low resistivity values (e.g. fresh or saline water depending the resistivity). The pr ocessing of one dimensional model produces a $2 \mathrm{D}$ image that allows the user to get more detailed $\mathrm{i}$ nformation of the study area. The results for both (North and South) sections (as depicted in Figure 3, red squares) are presented in Figure (5). Moreover, both TEM pseudo sections were correlated with the available geological, hydrogeological and borehole logs information of the investigated ar ea, in order to have the optimal reconstructed model for the study area.
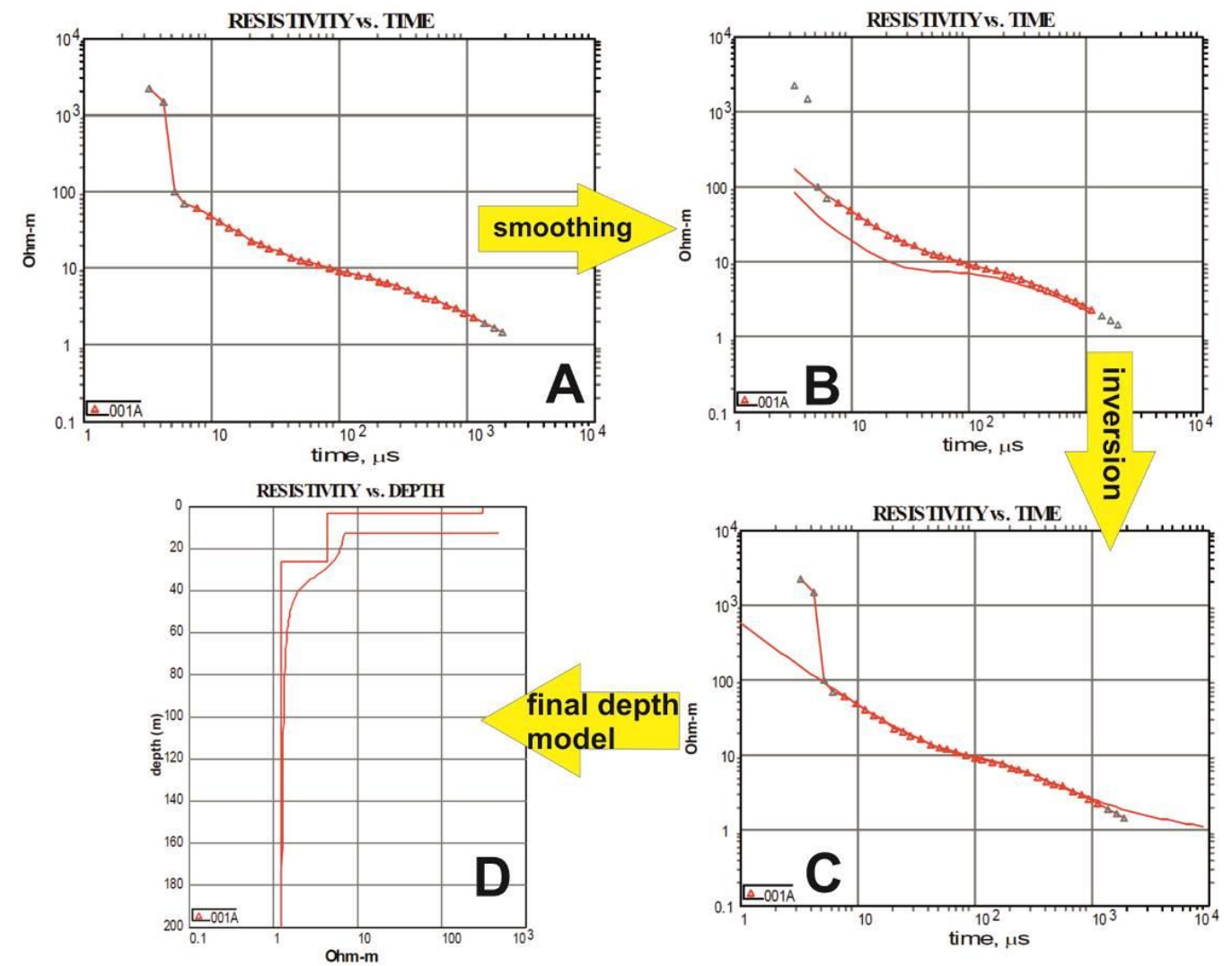

Figure 4 - A) Raw data for TEM sounding. Outlier points detected and marked grey in order the user to be able to easily reject them, if needed. On the horizontal axis the time $(\mu \mathrm{s})$ is depicted and on the vertical axis the apparent resistivity (Ohm-m) is shown. B) The sounding after smoothing. The new orange solid lines represent the apparent resistivity from asymptotic formula ( $\rho(t)$ - medium line) and from transient formula ( $(\mathrm{f}(\mathrm{t})$ - bottom line), $\mathrm{C}$ ) Final resistivity vs time response of the resulted 1D model produced by the inversion and $D$ ) 1D representation of the inversion model. The transformation and inversion are presented in a smooth curve and the piecewise-uniform diagram respectively. 
In total, eight borehole logs were used for the verification of the resulted geophysical model and th ree fracture zones were defined as a lateral resistivity discontinuity of the final reconstructed pseud o-2D models, as shown in Figure 5. The geophysical pseudo resistivity sections were in good agree ment with the information acquired from borehole logs. In the geophysical sections (Figure 5, Nort $\mathrm{h}$ and South profile), four main categories of rocks dominated: a) quaternary deposits composed of unsaturated sand and gravels (unit A) with an average thickness of about 35-45 meters and resistivi ty varying between 80-300 Ohm.m, b) neogene sediments composed of marls with some sand and conglomerates (unit B) with resistivities of 10-50 Ohm.m, c) marls (unit C) corresponding to the lo west resistivity values (less than $1 \mathrm{Ohm} . \mathrm{m}$ ) and d) marly limestone (unit D) with resistivities aroun d 300 Ohm.m. From the tectonic point of view, two fracture zones were detected (as lateral resistiv ity discontinuity), into the North and South geoelectrical sections. These tectonic findings can be c onsidered as concealed faults and partly verified by the most updated geological maps and the deta iled digital elevation model (DEM) of the study area.
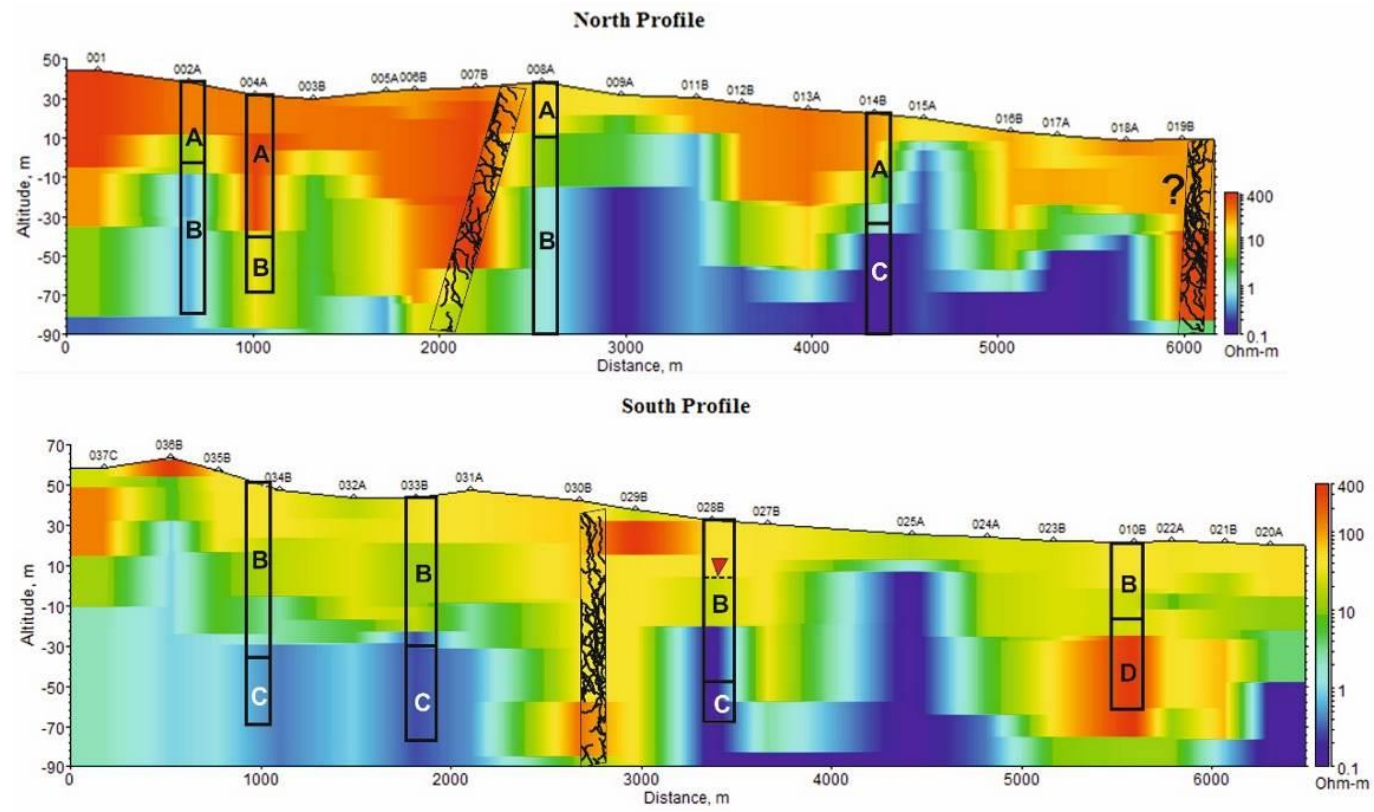
A : sand and gravels
Legend $\mathrm{C}$ : Marl
B : Marl with sand/conglomerates
D : Marly limestone

Figure 5 - Pseudo-2D modeling of TEM data is presented for the North and South Profiles across the Chania basin. The detected fracture zones and the possible tectonic features (using question mark, ?) are also depicted. Eight borehole logs are also presented.

\section{Discussion}

Sarris et al. (2005) detected three fault zones (blue ellipses in Figure 6) at the southern part (foot hill of the mountainous area of Chania) of the Chania/Souda basin by using the VLF geophysical method. Papadopoulos (2013), has applied deep electrical resistivity tomography (ERT) (till the depth of 120 meters) and one fracture zone (green ellipse in Figure 6) in the middle of the ERT profile was defined. In the framework of this work, three fracture zones were depicted (red ellipses in Figure 6). The first two (marked with F) fracture zones are well correlated with the defined by previous geophysical studies tectonic features. The third tectonic feature (marked with a question mark, ? at the eastern part of the basin) can be assumed as a new fault which can be correlated with the appearance of the limestone in the area that depict a possible N-S direction fault. 


\section{Conclusion}

The contribution of the presented geophysical research is that it provides preliminary knowledge of the current tectonic regime of Chania/Souda basin by applying modern geophysical methods. The use of surface geophysics as one of the primary tools for a large-scale tectonic investigation, especially as a rapid and cost effective set of methods that can determine a complex tectonic system is shown.

Specifically, results from TEM measurements were evaluated and calibrated using borehole data at numerous locations. Then, by means of 2D pseudosections, formations and new faults were evaluated and identified. A detailed knowledge of the geological and tectonic characteristics of a study area can be used for any future seismotectonic and earthquake vulnerability study of the area under investigation.

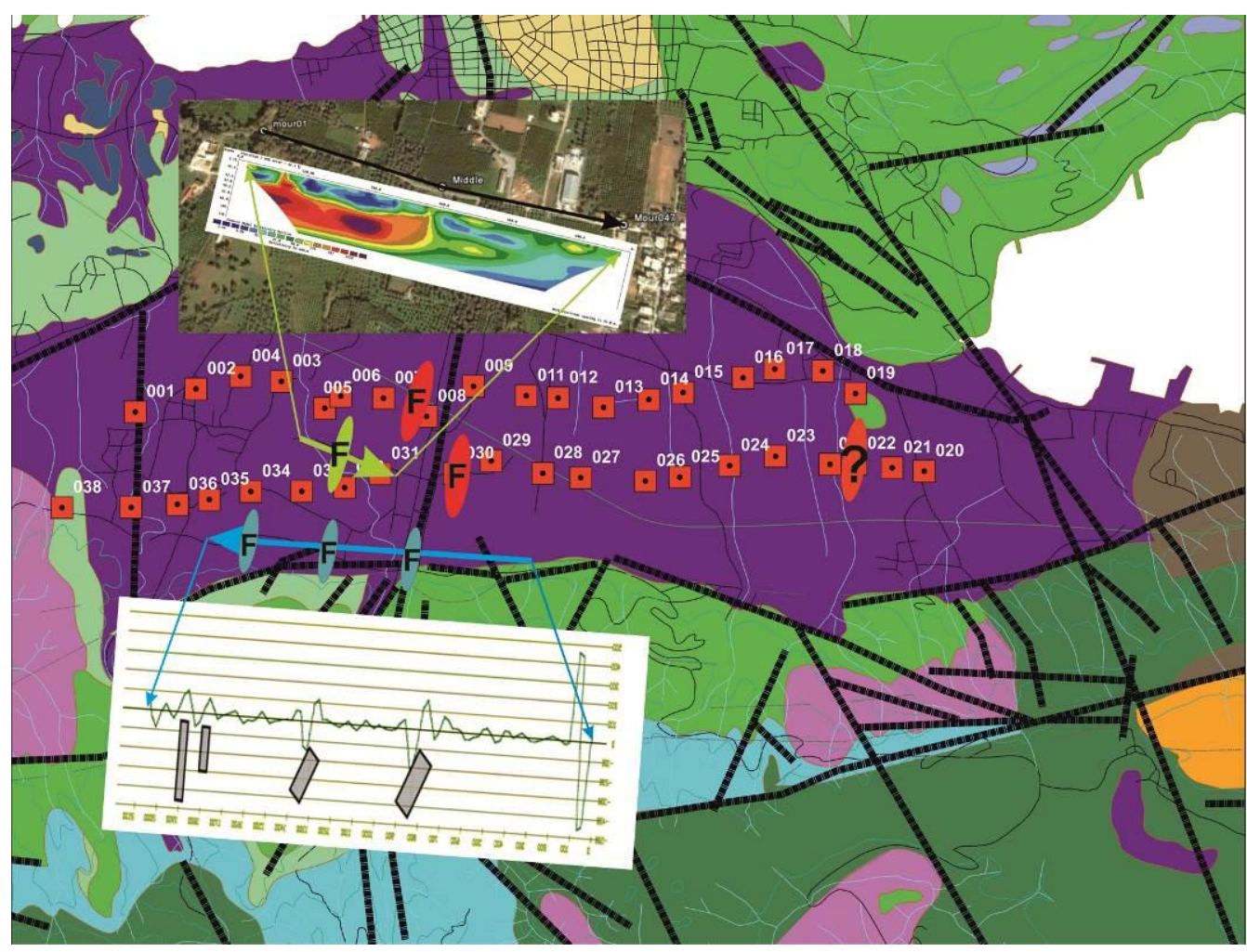

Figure 6 - Integrated interpretation of different geophysical measurements/methods (ERT, VLF and TEM) is presented. Colored ellipses represented the location and direction of the detected (by the geophysical method) fracture zones.

\section{Acknowledgments}

This project is implemented through the Archimedes III, project title: Interdisciplinary study for exploring, understanding and management of groundwater resources. Pilot field investigation NorthWestern and Central Crete (AQUADAM). 


\section{References}

Barsukov, P.O., Fainberg, E.B. and Khabensky, E.O., 2007. Shallow investigation by TEM-FAST technique: methodology and case histories. In: Spichak, V.V., ed., Methods of geochemistry and geophysics, Elsevier, 55-77.

Koutsoupakis, I., Raptakis, D., Soupios, P. and Vafidis, A., 2013. Preliminary Vs30 spatial distribution of Chania city, Greece based on MAM measurements, 20th International Geophysical Congress and Exhibition of Turkey, 25-27 November 2013, Antalya, Turkey.

Mountrakis, D., Kilias, A., Pavlaki, A., Fassoulas, Ch., Thomaidou, E., Papazachos, C., Papaioannou, Ch. and Roumelioti, Z., 2012. Neotectonic study of Western Crete and implications for seismic hazard assessment, Journal of the Virtual Explorer, 42(2).

Papadopoulos, I., 2013. Experimental and theoretical Study of local surface amplification using microtremor data and field geophysical measurements, PhD in Geophysics and Engineering Seismology, Geology Department, School of Earth Sciences, Aristotle University of Thessaloniki.

Papadopoulous, I., Papazachos, C., Savvaidis, A., Theodoulidis, N. and Vallianatos, F., 2016. Seismic Response of the Broader Chania Basin Area (Southern Greece) from the Joint Evaluation of Ambient Noise and Earthquake Recordings, Bulletin of Earthquake Engineering.

Sarris, A., Karakoudis, S., Bidaki, X. and Soupios, P., 2005. Study of the Morphological Attributes of Crete through the Use of Remote Sensing Techniques, IASME Trans, 2(6), 1043-1051, ISSN 1790-031X, August 2005. 